\title{
Hepatopetal Portal Venous Flow
}

National Cancer Institute

\section{Source}

National Cancer Institute. Hepatopetal Portal Venous Flow. NCI Thesaurus. Code

C126426.

The normal pattern of blood flow towards the liver through the portal vein. 